\title{
Persistent biological reactivity of quartz in the lung: raised protease burden compared with a non-pathogenic mineral dust and microbial particles
}

\author{
Geraldine M Brown, David M Brown, Joan Slight, Kenneth Donaldson
}

\section{Abstract}

This study assessed the potential harmfulness of particles in the lung by measuring their ability to elicit and maintain an inflammatory response and to damage lung tissue. It compared the inflammogenicity of two nondurable, biological particulates (Corynebacterium parvum and zymosan) with a pathogenic mineral dust (quartz) and a nonpathogenic dust (titanium dioxide) by dosing rats via the intratracheal route and measuring the consequent alveolitis. The magnitude and duration of the inflammatory response were assessed by measuring the total number of leucocytes and the percentage of neutrophils obtained by bronchoalveolar lavage. Two key functional parameters of the lavaged leucocytes-ability to degrade fibronectin and production of plasminogen activator-were also measured. A marked inflammatory response had occurred by one day after instillation, characterised by increases in total leucocyte numbers and percentage of neutrophils in the bronchoalveolar lavages, with all four test materials. In all but the quartz exposed animals, the inflammation subsided rapidly thereafter, approaching control levels by 15 days after injection; in the quartz exposed animals the alveolitis persisted for up to $\mathbf{3 0}$ days. All of the inflammogens generated chemotaxins in rat serum in vitro and so, by analogy, might also be expected to generate chemotactic activity in alveolar lining fluid which could contribute to the generation of an inflammatory response. The cellular inflammatory response was accompanied by a concomitant increase in the proteolytic activity of the bronchoalveolar lavage

Institute of Occupational Medicine Limited, 8 Roxburgh Place, Edinburgh EH8 9SU

G M Brown, D M Brown, J Slight, K Donaldson leucocytes but production of plasminogen activator remained unchanged. In vitro exposure to the inflammogens had no effect on the proteolytic activity against fibronectin or on the plasminogen activator activity of bronchoalveolar leucocytes.

Among the fibrotic lung diseases of known aetiology are those associated with chronic exposure to harmful mineral dusts-for example, silica (silicosis), asbestos (asbestosis), and coalmine dust (coalworkers' pneumoconiosis). ${ }^{1}$ Exposure to such dusts is associated with the accumulation of inflammatory leucocytes in the alveolar region in exposed workers ${ }^{23}$ and in animal models of lung disease. ${ }^{45}$ The inflammatory response may be mediated, in part, by the action of leucocyte derived plasminogen activator in converting plasminogen to plasmin, a protease with potent inflammogenic properties. ${ }^{6}$ Recruitment of leucocytes in response to deposition of particles in the lung may also occur through direct activation of complement by the particles in the alveolar lining fluid. ${ }^{7}$ Toxic products and growth factors are released in increased quantities by inflammatory leucocytes at sites of inflammation in the lungs and so "bystander injury" to the surrounding host tissue and consequent overgrowth of mesenchymal cells are likely to result. Leucocyte proteases are considered to play a major part in this type of injury ${ }^{8}$ and have been found in increased amounts in the bronchoalveolar lavage fluid of patients with fibrotic lung disease. ${ }^{910}$ Proteolysis of connective tissue components by leucocyte proteases is likely to be central to the pathogenesis of chronic inflammatory lung disease as suggested by studies demonstrating connective tissue proteolysis by inflammatory leucocytes in vitro ${ }^{11} 12$ and by leucocyte proteases in vitro ${ }^{13}$ and in vivo. ${ }^{14}$ The degree of tissue injury is associated with the number of inflammatory leucocytes in the alveolar region $^{6}$ and thus the severity of tissue damage is likely to be related to both the magnitude and duration of the alveolitis and to the cellular profile of the bronchoalveolar leucocytes.

In this study, we have considered key aspects of the 
inflammatory response to particle deposition in the lung. We compared the inflammation engendered by two non-durable, biological particulates, Corynebacterium parvum (a heat killed bacterial preparation) and zymosan (an extract of yeast cell walls) with that evoked by the inert dust, titanium dioxide $\left(\mathrm{TiO}_{2}\right)$, or by a pathogenic dust, quartz; these are nonbiodegradable particles. Titanium dioxide is a particulate that is widely used in the food and paint industries but has not been associated with pathology in occupationally exposed groups; it is commonly used as an "inert" control dust in experimental studies in vitro ${ }^{1516}$ and in vivo. ${ }^{517}$ By contrast, occupational exposure to quartz is known to be associated with development of the fibrotic lung disease, silicosis, and quartz has been shown to have potent cytotoxic effects in vitro ${ }^{18}$ and marked inflammogenic potential. ${ }^{5}$

The magnitude and duration of the alveolitis produced by these inflammogens was assessed using bronchoalveolar lavages; two key parameters of leucocyte protease activity, relevant to the inflammatory response, were then measured: (a) ability to degrade fibronectin, a connective tissue component of importance in maintaining tissue integrity in the lung and $(b)$ production of plasminogen activator, a protease that converts plasminogen to plasmin and that may thus be central to the development of the inflammatory response. Also, to assess the contribution that dust might make directly to lung inflammation, we measured the inherent ability of the dust to activate complement. To more closely mimic the situation in vivo, with continuing dust exposure, we further exposed leucocytes to the inflammogens in vitro after previous in vivo exposure. The protease activity of these "twice challenged" leucocytes was assessed to see if a second challenge with inflammogen enhanced that activity.

The harmful effects of the in vivo treatments were assessed microscopically on fixed and stained sections of the lung tissue.

\section{Materials and methods}

ANIMALS

The rats used were syngeneic, SPF males of the PVG strain, obtained from the breeding unit of the Institute of Occupational Medicine.

\section{REAGENTS}

Iodine $^{125}$ was obtained from Amersham Limited (Aylesbury, Buckinghamshire). Human plasma fibronectin, fibrinogen, and bovine serum albumin were purchased from Sigma Ltd, Poole, Dorset. Plasminogen was obtained from Kabi (Flow Laboratories, Rickmansworth, Herts). Hams F10 medium and phosphate buffered saline (PBS) were purchased from Gibco BRL (Paisley, Renfrewshire).

\section{PARTICULATES}

The quartz sample used was the DQ12 standard; $\mathrm{TiO}_{2}$ (rutile) was obtained from Tioxide Ltd, Stockton-on-Tees. Corynebacterium parvum, a heat killed bacterial preparation was purchased from Wellcome Laboratories Ltd, Beckenham, Kent; and zymosan, which is a preparation of yeast cell walls, was obtained from Sigma, Poole, Dorset.

IN VIVO DUST EXPOSURE AND LAVAGE

Rats were injected intratracheally with $1 \mathrm{mg}$ of quartz, $\mathrm{TiO}_{2}$, or zymosan in $0.5 \mathrm{ml} \mathrm{PBS}$, or $1.4 \mathrm{mg} C$ parvum as a $0.2 \mathrm{ml}$ suspension. One, three, five, 15 , or 30 days thereafter, groups of three treated rats and three untreated control rats were killed and the lungs lavaged with warm saline to retrieve the bronchoalveolar leucocytes as previously described. ${ }^{5}$ Total and differential counts were performed on the harvested leucocytes.

\section{FIBRONECTIN PROTEOLYSIS}

The ability of bronchoalveolar leucocytes, or their supernatants, to degrade fibronectin was assessed by measuring breakdown of a solid phase ${ }^{125} I$ fibronectin matrix as previously described. ${ }^{12}$ Proteolytic activity was measured as counts per min of degraded ${ }^{125} I$ fibronectin released into the supernatant medium over a four hour period. To overcome interexperiment variation due to decreasing counts of ${ }^{125} I$ in the fibronectin coated plates with time, results are presented as a percentage of background proteolysis.

\section{PLASMINOGEN ACTIVATOR ASSAY}

Production of plasminogen activator was measured as previously described ${ }^{19}$ by measuring plasminogen dependent breakdown of ${ }^{125}$ I fibrin. Fibrinolysis was measured as counts per min of ${ }^{125} \mathrm{I}$ fibrin released into the supernatant medium in a 24 hour period.

\section{IN VITRO TREATMENT WITH PARTICULATE OR SOLUBLE TRIGGERS}

Bronchoalveolar leucocytes from particulate exposed or control rats were assayed in the fibronectin proteolysis and plasminogen activator assays in the presence of zymosan, $\mathrm{TiO}_{2}$, or quartz at $0 \cdot 01,0 \cdot 1$, or $1.0 \mathrm{mg} / \mathrm{ml}$, or phorbol myristate acetate (PMA) at $0 \cdot 1,1 \cdot 0$, or $10 \mu \mathrm{g} / \mathrm{ml}$, to assess the effect of such treatment in modulating the activity of the leucocytes.

\section{CHEMOTAXIS}

Particulates were incubated at $1 \mathrm{mg} / \mathrm{ml}$ in rat serum for one hour at $37^{\circ} \mathrm{C}$ followed by heat inactivation at $56^{\circ} \mathrm{C}$ for one hour; the particles were then removed by centrifugation at $3000 \mathrm{rpm}$ for 10 minutes. Generation of chemotactic activity in the serum was assessed by measuring its ability to induce chemotaxis of control rat alveolar macrophages in Blindwell chambers as previously described. ${ }^{20}$ 
STATISTICAL ANALYSIS

There was minimum day to day variation in total numbers of leucocytes or percentage of neutrophils in bronchoalveolar lavage of control animals, so comparisons of these two parameters between treatment groups and controls at one day after injection were made with pooled control data (12 animals). Differences were tested by Student's $t$ test and the least significant difference reported.

\section{HISTOLOGY}

Tissue samples were prepared for histology at the 30 day time point. Lungs were fixed subsequent to lavage by inflating them with $10 \%$ formol saline before routine processing for histology. Whole lung sections were cut by microtome and stained with haemotoxylin and eosin to visualise the tissue.

\section{Results}

TOTAL LEUCOCYTES IN BRONCHOALVEOLAR LAVAGES

All the inflammogens provoked a transient peak of leucocyte recruitment one day after injection (fig 1); this was greatest with $C$ parvum and least with $\mathrm{TiO}_{2}$. The difference between the pooled data from all controls and each treatment group was compared at one day and was highly significant $(p<0.001)$. The magnitude of the response to quartz was similar to that produced by zymosan at one day, but after a slight decrease in bronchoalveolar lavage leucocytes at three days, numbers of leucocytes in lavages from quartz dosed rats escalated and were 10 -fold greater than controls at 30 days.

\section{PERCENTAGE OF NEUTROPHILS IN BRONCHOALVEOLAR LAVAGES}

The percentage of neutrophils in the cell populations from lavages reflected a typical acute inflammatory response (fig 2). A pronounced influx of neutrophils occurred at one day with each particulate and this was highly significant compared with the pooled control data $(p<0.005)$. In all but the quartz dosed animals, the numbers of neutrophils returned rapidly to background levels; the percentage of neutrophils in quartz elicited leucocytes persisted at around 30\% for the 30 days of the experiment (significantly greater than controls, $\mathrm{p}<0.001)$.

\section{FIBRONECTIN DEGRADING ACTIVITY OF LEUCOCYTES IN} BRONCHOALVEOLAR LAVAGES

The proteolytic activity of the leucocytes in lavages reflected the cellular response, peaking at one day with all of the inflammogens ( $p<0.001$ ) (fig 3) and, with the exception of those from the quartz exposed group, returning rapidly to normal thereafter. Proteolysis of fibronectin by the quartz elicited leucocytes remained at least fivefold greater than that by control leucocytes for up to 30 days. The proteolytic activity of the inflammatory leucocytes, on a per cell basis, is an insufficient descriptor of the

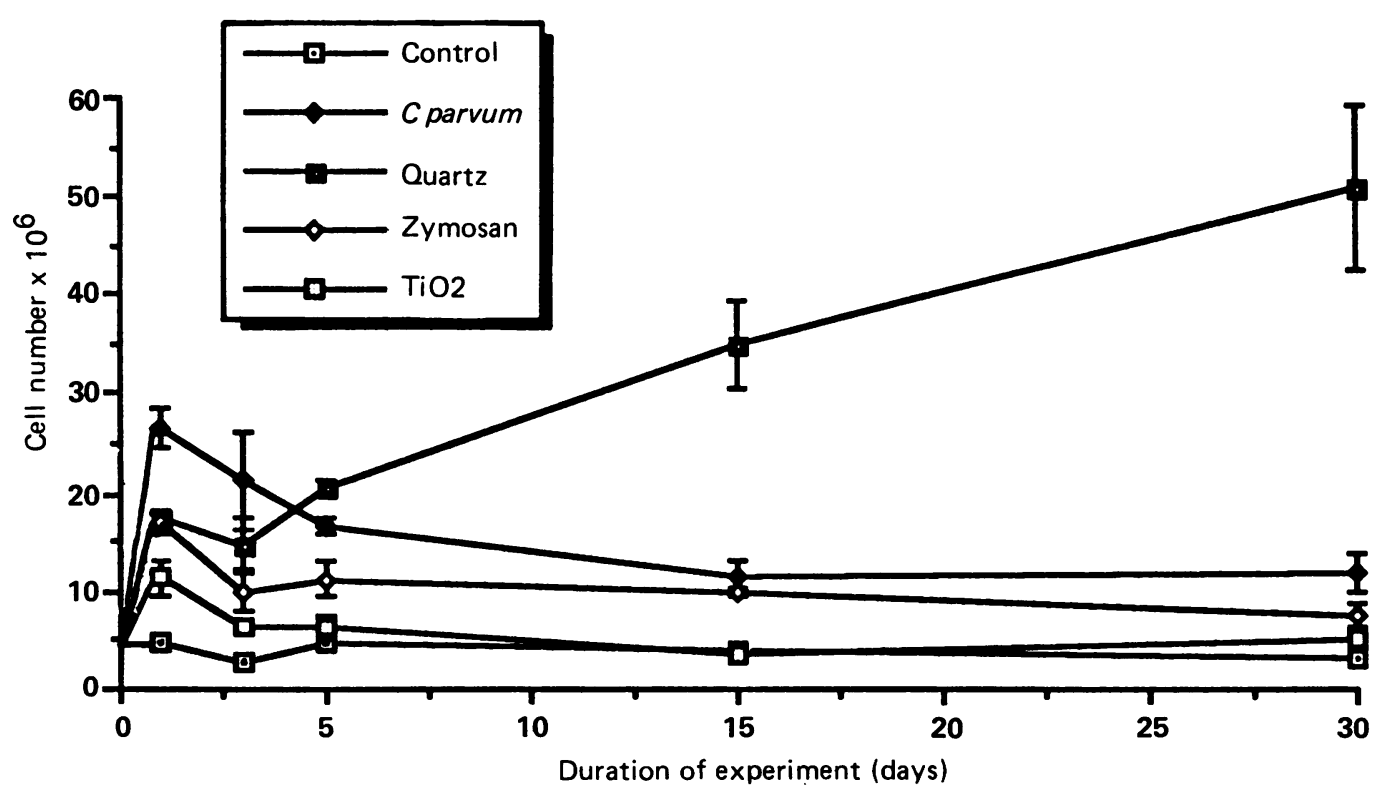

Figure 1 Total cells in lavage fluid with time following deposition of a single bolus of the inflammogen on day 0. Results are mean (SE) from three rats per sample at each time point. 


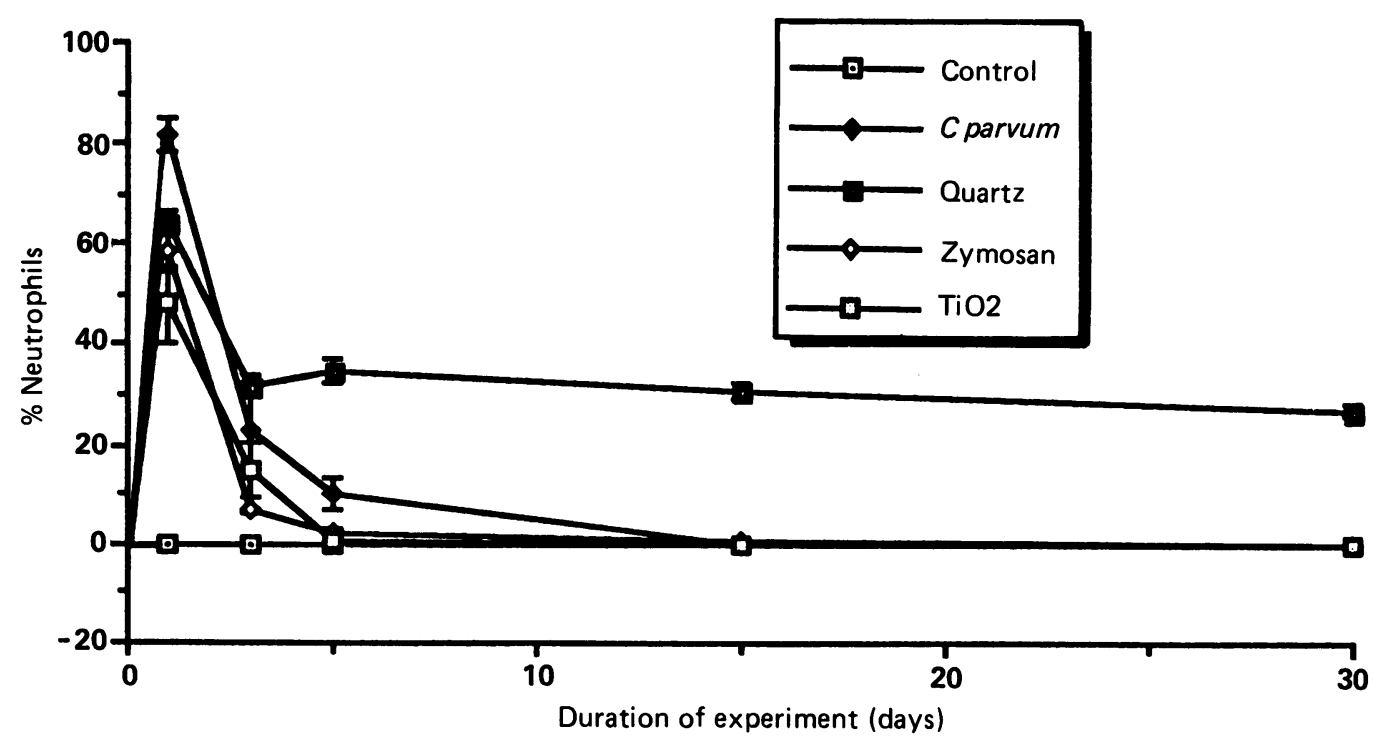

Figure 2 Percentage of neutrophils in lavage fluid with time following deposition of a single bolus of the inflammogen on day 0 . Results are mean ( $S E$ ) from three rats per sample at each time point.

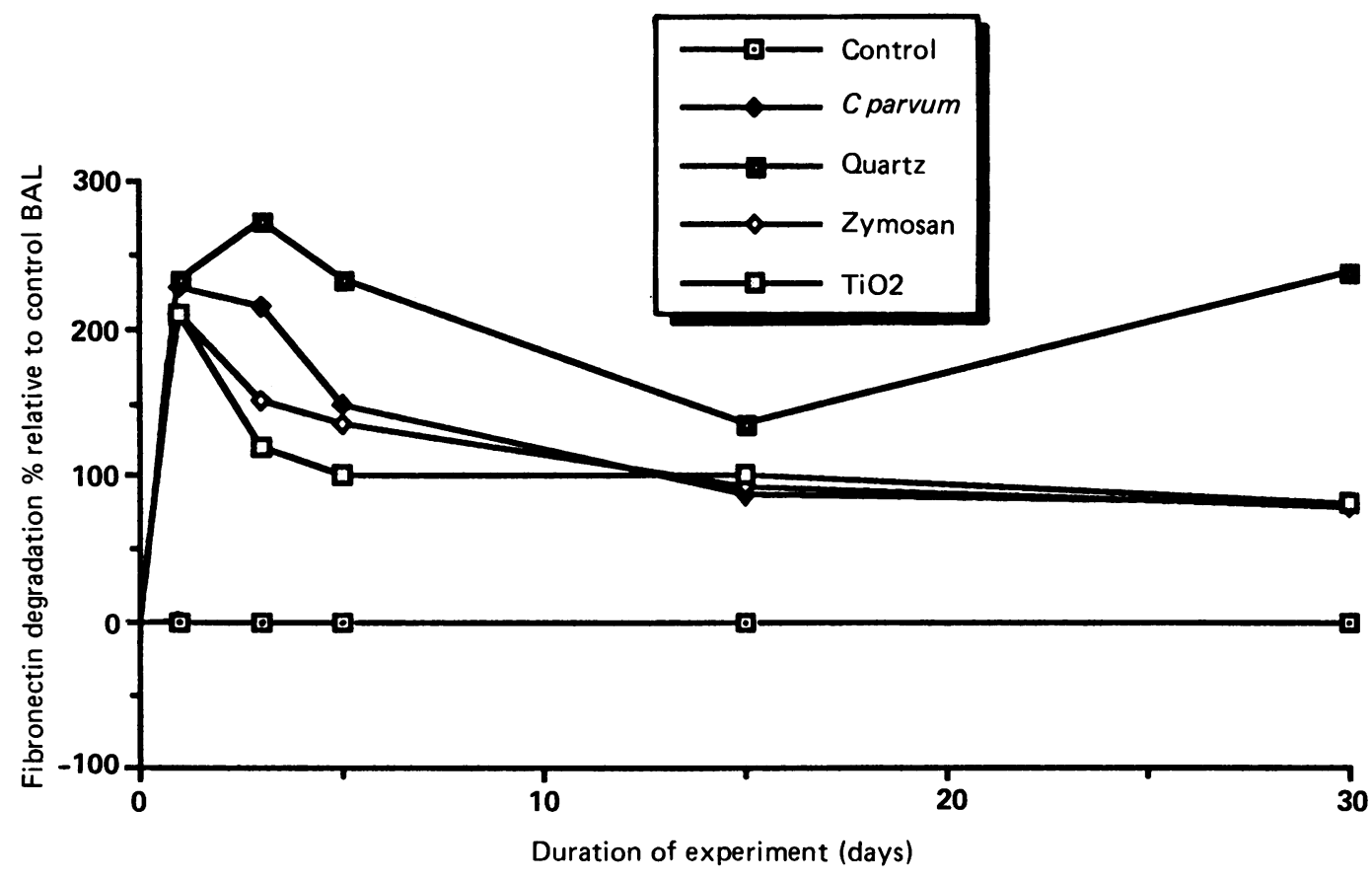

Figure 3 Proteolytic activity of inflammatory leucocytes with time after deposition of a single bolus of the inflammogen on day 0 . Results are expressed as fibronectin proteolysis as a percentage of control cell activity and are the mean (SE) of three wells per sample and three animals per sample at each time point. BAL = bronchoalveolar lavage. 


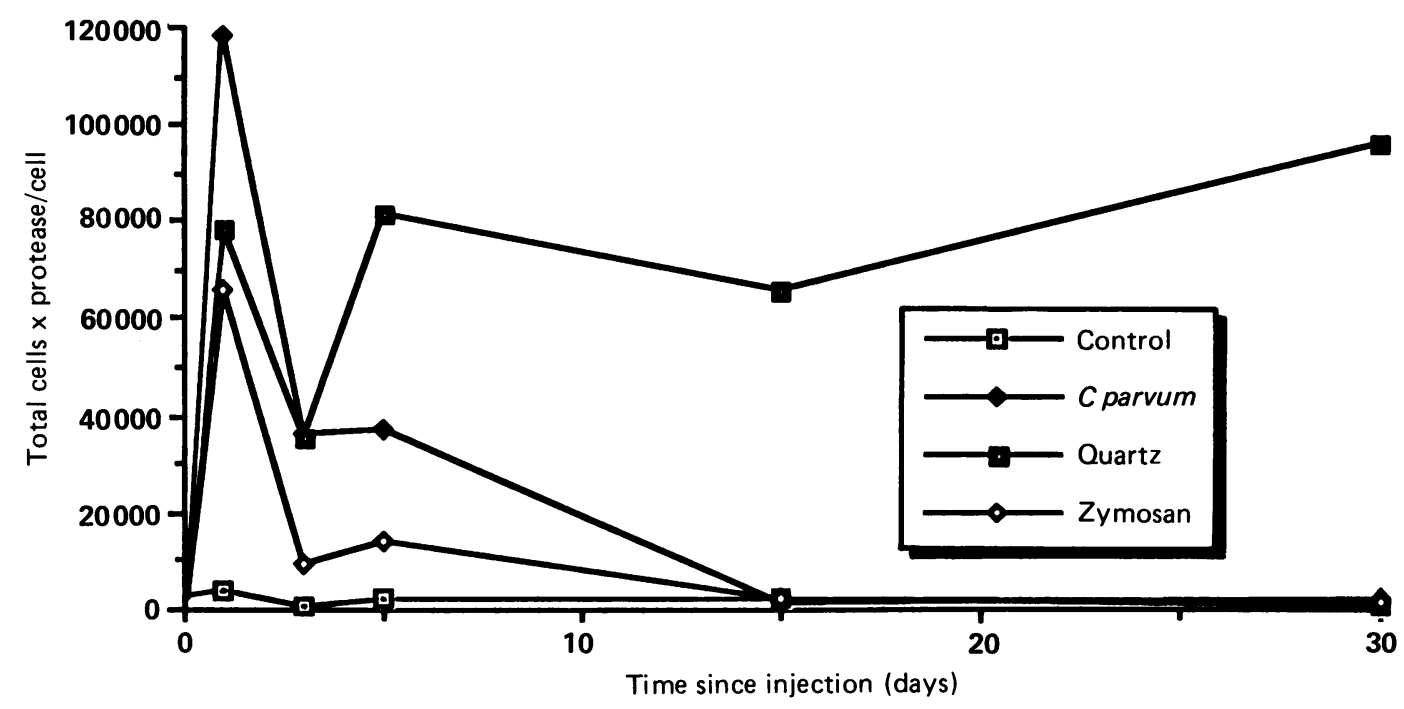

Figure 4 Bronchoalveolar leucocyte protease burden obtained by multiplying the total number of leucocytes in the lavage by the proteolytic activity per leucocyte. Results are expressed as total counts per minute of degraded fibronectin released.

potential protease burden in the alveolar region as there was substantial recruitment of inflammatory leucocytes. We therefore calculated the putative total protease burden of the lung by multiplying the proteolytic activity per leucocyte by the total number of leucocytes in the bronchoalveolar lavage (fig 4); this gave us a measure of the overall proteolytic potential of the lavage cells. The levels were greatest one day after injection, when the cellular influx was at its peak; $C$ parvum had most activity at this time but quickly returned to much lower levels; only the quartz sample showed a prolonged increase which was 87 -fold greater than all other samples 30 days after injection.

Exposing the control or inflammatory bronchoalveolar leucocytes to $\mathrm{TiO}_{2}$, quartz, zymosan, and PMA in vitro had no effect on their proteolytic activity, irrespective of the preceding in vivo treatment (results not shown).

\section{PLASMINOGEN ACTIVATOR ACTIVITY}

Plasminogen activator activity was not increased by in vivo treatment with any of the particles, nor was there any increase following in vitro exposure of the bronchoalveolar leucocytes to $\mathrm{TiO}_{2}$, quartz, zymosan, or PMA (results not shown).

\section{ABILITY OF PARTICLES TO GENERATE CHEMOTAXINS IN} SERUM

The two biological particulates, $C$ parvum and zymosan, had the greatest effect in generating chemotaxins in normal rat serum (table). The sera treated with quartz and $\mathrm{TiO}_{2}$ were considerably less active but still engendered three to four times more chemotaxis than untreated rat serum; the differences between the control and treated sera were significant at $\mathrm{p}<0.001$.

\section{TISSUE RESPONSE TO PARTICULATE EXPOSURE}

At the 30 day time point no evidence of tissue damage was found in any of the treatment groups, except quartz. In the quartz dosed animals, however, there was considerable damage. Areas of alveolar lipoproteinosis were evident in conjunction with hyperplasia of the septal epithelium (fig 5).

Chemotaxis of control rat alveolar macrophages towards particle activated serum. Results are mean (SD) of migrated cells in 10 high power fields

\begin{tabular}{llllllll}
\hline & \multicolumn{2}{l}{ Particle treatment of serum } & & & & \\
\cline { 2 - 7 } & None & C parvum & Zymosan & Quartz & TiO \\
\hline Cell number & 3.7 & $(2 \cdot 0)$ & $59 \cdot 4(4 \cdot 0)$ & $73 \cdot 2 \quad(8 \cdot 5)$ & $16 \cdot 3 \quad(5 \cdot 4)$ & $12 \cdot 0 \quad(3 \cdot 7)$ \\
\hline
\end{tabular}




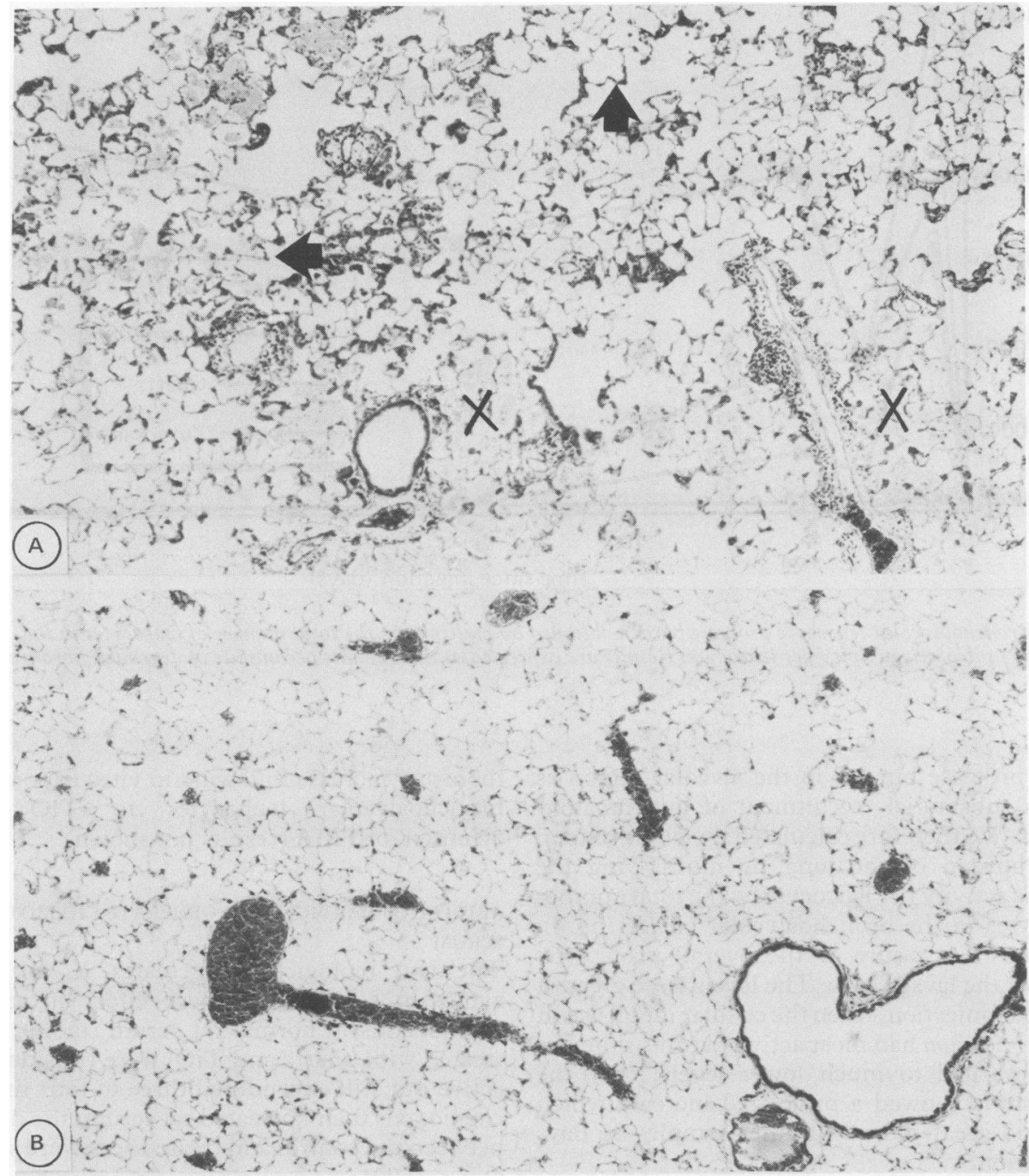

Figure 5 Tissue response 30 days after intratracheal instillation of $1 \mathrm{mg}$ quartz $(\times 500$ magnification). $A$, quartz dosed lung; $B$, control lung. Areas of alveolar lipoproteinosis $(X)$ and type II cell hyperplasia (arrows) are extensive in $(A)$.

\section{Discussion}

Three key factors could determine the persistence of lung inflammation in response to mineral dust: (1) intensity of inhalation exposure to particles (dose and duration of exposure), (2) deposition and retention of harmful particles within the alveolar region, and (3) persistence of the ability of particles retained in the lung to impart harm to the tissue. We have previously considered the effects of intensity of exposure to mineral dust in causing inflammation of the lung ${ }^{21}$ and interstitial fibrosis ${ }^{22}$ and have shown that both are time and dose related. We have also assessed the ability of particles to persist within lung tissue by measuring clearance rates following inhalation exposure and have shown that over the time scale we have used in the present study, little difference is evident in the clearance rates for harmful and nonharmful dusts. ${ }^{23}$ Thus the major descriptor of the harmfulness of a dust may be the retention of its biological reactivity in the lung.

In this paper, we have considered the key parameters of persistence and reactivity of dust by assessing the magnitude and duration of the inflammatory response in rat lungs following a single intratracheal instillation of particles of different biological reactivity and durability. We have shown that deposition of particulate matter in the lung evokes an inflammatory response. This is true 
whether the particulate is a typical biological inflammogen such as $C$ parvum or zymosan (both of which are non-durable particles), or whether it is a harmful mineral dust, quartz, or the inert dust, titanium dioxide (both are non-degradable). Leukocyte chemotaxins are secreted by macrophages in response to a phagocytic stimulus ${ }^{2324}$ and this may account for the large influx of leucocytes one day after intratracheal injection. There may also be a direct role, however, for extracellular particles in influencing leucocyte recruitment as all the inflammogens could generate chemotaxins in serum. Our earlier work has shown that this chemotactic activity is generated by cleavage of the complement component, $\mathrm{C} 3$ and production of $\mathrm{C} 5 .^{20}$ Because alveolar lining fluid contains $\mathrm{C} 3,{ }^{25}$ particles may activate complement at the alveolar surface ${ }^{7}$ and so contribute directly to recruitment of leucocytes. We have shown in the present study, however, that this mechanism is not the primary source of chemotaxins as the extent of complement activation by particles was not correlated with the Inagnitude of the response to those particles in vivo. Most particles depositing in the lung are cleared within one to two days by phagocytosis ${ }^{26}$ or by extracellular transfer to lymph nodes. ${ }^{27}$ The reduction in inflammation from one day onwards with three of the particulates thus supports the theory that phagocytosis (with attendant secretion of chemotaxins by the phagocytosing leucocytes) and complement activation by free particles may be important mechanisms in generating the initial acute inflammatory response. Inflammation in response to injection of quartz did not, however, subside after one day but increased up to 30 days after injection when there were 10-fold more leucocytes in the bronchoalveolar lavages of quartz exposed animals than in the controls or in the other exposed groups. We have recently produced evidence that the alveolitis persists up to 48 days after injection. ${ }^{28}$ So, alternative explanations must be sought for the sustained inflammogenic properties of quartz.

A commonly invoked mechanism is that the pathogenic potential of a particle is related to its toxicity ${ }^{29}$ but other mechanisms may also be implicated in dust induced inflammation in the lung. We have previously shown that leucocytes lavaged from rats exposed to quartz by inhalation were more than $99 \%$ viable ${ }^{21}$ and remained so during 24 hours of culture in vitro. Similarly, in the present study, the lavaged leucocytes were also more than $99 \%$ viable for all particulates after intratracheal exposure (results not published). Studies exposing alveolar macrophages from control rats to low concentrations of quartz in vitro also showed that the cells remained viable, although increasing the concentration of quartz did lead to cell death. ${ }^{16} \mathrm{We}$ therefore propose a further mechanism for the persistence of quartz induced inflammation in the lung. The surface of quartz particles is highly reactive and interacts with cell membranes by acting as a hydrogen donor. ${ }^{30}$ This may be the means whereby quartz kills cells at high concentrations, but at low concentrations, where the macrophages remain viable, interaction of intracellular quartz with cell components may lead to macrophage activation with its attendant consequences for enhancing the inflammatory response. We have shown previously that bronchoalveolar leucocytes from rats exposed to silica secrete increased amounts of interleukin- $1 .^{31}$ Also, macrophages cultured in vitro in the presence of silica release interleukin- $1,{ }^{3132}$ leucocyte chemotaxins, ${ }^{24}$ and fibroblast growth factor..$^{33}$

Plasminogen activator is released by activated macrophages and is cited as being central to the inflammatory response. ${ }^{6}$ In our rat model, there was no measurable change in production of plasminogen activator with any of the inflammogens at any time. This suggests that plasminogen activator plays a minor role in the inflammatory response to particulates in rat lung. As alveolitis and tissue damage in the quartz dosed rats were pronounced for up to 30 days after exposure, these results indicate that whereas plasminogen activator may play a part in the disease process in other models or in man, it need not be essential for tissue damage to occur. Other proteases released by inflammatory leucocytes may, however, play a part in the inflammatory response. These are the connective tissue proteases (elastase, collagenase, etc), which can act on connective tissue to generate fragments that are leucocyte chemotaxins. ${ }^{34}{ }^{35}$ Proteases may also enhance inflammation by activating components of complement ${ }^{36}$ and in the long term, are thought to have a major part in the remodelling of connective tissue components that is associated with pathological change in the lungs.

In this study, we have shown that inflammatory bronchoalveolar leucocytes have enhanced ability to degrade the connective tissue component fibronectin compared with resident alveolar macrophages. We have also shown previously that other connective tissue molecules (collagen and laminin) can be similarly degraded by these cells. ${ }^{12}$ The assay we used is representative of the type of interaction that might occur in the lung parenchyma where leucocytes come into close contact with the extracellular matrix. Increases in the observed proteolytic activity of the leucocytes tended to reflect the neutrophil content of the lavaged populations but there was residual increased proteolytic activity from 15 days onwards with all of the particles, when there were only neutrophils in the quartz elicited population. We have shown previously that inflammatory macrophages also exhibit enhanced proteolytic activity compared with resident alveolar macrophages. ${ }^{12}$ Thus the persistently increased proteolytic activity from 15 days onwards is likely to be due to persis- 
tence of activated macrophages. Our results are in agreement with previously published work where experimental exposure to particulates led to enhanced protease production by leucocytes in vitro both experimentally ${ }^{37}$ and in bronchoalveolar lavage from occupationally exposed men. ${ }^{38}$

Our studies have shown a substantial increase in connective tissue protease per leucocyte during inflammation; also the number of leucocytes was dramatically increased. Taken together, these produce a potential leucocyte burden that is the product of the two variables. A calculation of the leucocyte protease burden (leucocyte protease burden $=$ total cells $\times$ protease per cell) showed that 30 days after exposure to quartz there was an 87-fold increase in this parameter compared with controls. Whereas the leucocyte protease burden was increased during the acute inflammatory response to the biological particulates and $\mathrm{TiO}_{2}$ as well as quartz, only quartz caused a sustained increase. The leucocyte protease burden of the four types of particle in this assay system are related in their pathological potential in man. Acute lung inflammation induced by bacterial infection is not usually associated with long term pathological change, even in pneumonia where there can be up to $70 \%$ neutrophils and substantial increases in total numbers of leucocytes in the lavage. ${ }^{3}$ Similarly, $\mathrm{TiO}_{2}$, despite widespread industrial use, is not associated with long term pathology in occupationally exposed workers, ${ }^{39}$ nor did it evoke a persistent inflammatory response in our rat model. It was actually less inflammogenic than the two microbial particulates. The only material which elicited a persistent inflammatory response was quartz. Development of silicosis in exposed workers where there is a very low level of alveolar inflammation ${ }^{3}$ is likely, therefore, to be related to the persistence of that alveolitis. Indeed, the progressive nature of the inflammatory response in our experiments following a single intratracheal injection of quartz may yield some information regarding the progressive nature of silicosis, even when exposure ceases. ${ }^{1}$

The proteolytic activity of the leucocyte populations in the present study was not enhanced by further exposure to particles for four hours in vitro. Thus, phagocytosis of dust is not the sole trigger of leucocyte proteolytic activity, but it may act in conjunction with other in vivo signals such as tumour necrosis factor (TNF) or interleukin-1 to activate the leucocytes; TNF has multiple activities in modulating leucocyte function and has been reported to be secreted in increased amounts by blood monocytes of miners with coalworkers' pneumoconiosis. ${ }^{40}$

In summary, there was an initial acute inflammatory response to all of the particulates deposited in the alveolar region of the lung. This rapidly subsided with degradable biological particulates. The durable, non-harmful particulate, $\mathrm{TiO}_{2}$, also provoked only a transient inflammatory response but there was sustained inflammation in response to quartz. Thus durability of particles is not the major descriptor of their potential inflammogenicity. There is little evidence for differential clearance of $\mathrm{TiO}_{2}$ and quartz in the lung ${ }^{22}$ and so the difference in the inflammogenicity of $\mathrm{TiO}_{2}$ and quartz particles may reflect, primarily, differences in their biological reactivity. This may be due to the toxicity of quartz, causing cell death and consequent leucocyte recruitment, at high concentrations. Alternatively, or perhaps also, as the particle:cell ratio alters with increasing leucocyte recruitment, the number of particles per leucocyte may reach such a low level that the cell is not killed; the quartz particles may then remain sequestered within macrophages, so activating them and thus prolonging the inflammatory response.

This study suggests that the difference between harmful and non-harmful particles in the lung is related to their ability to exert a continuing inflammatory stimulus on the lung tissue. The pathology associated with occupational exposure to quartz is likely to be related to the low level alveolitis seen in silicotic subjects, causing a persistent increase in the overall protease burden in the lungs. The progression of the quartz-induced alveolitis which we have described may have some bearing on the progressive nature of silicosis.

This work was funded by the Colt Foundation.

1 Morgan WKC, Seaton A. Occupational lung disease. Philadelphia: WB Saunders, 1984.

2 Voisin C, Wallaert B, Aerts C, Grosbois JM. Bronchoalveolar lavage in coalworkers' pneumoconiosis: oxidant and antioxidant activities of alveolar macrophages. In: Beck EG, Bignon J, eds. In vitro effects of mineral dusts. Berlin: SpringerVerlag, 1985:93-100.

3 Begin R, Bisson G, Boileau R, Masse S. Assessment of disease activity by Gallium-67 scan and lung lavage in the pneumoconioses. Seminars in Respiratory Medicine 1986;7: 271-80.

4 Martin TR, Chi EY, Covert DA, et al. Comparative effects of inhaled volcanic ash and quartz in rats. Am Rev Respir Dis 1983;128:144-52.

5 Donaldson K, Bolton RE, Jones AD, et al. Kinetics of the bronchoalveolar leukocyte response in rats during exposure to equal airborne mass concentrations of quartz, chrysotile asbestos or titanium dioxide. Thorax 1988;43:525-33.

6 Hamilton JA. Macrophage stimulation and the inflammatory response to asbestos. Environ Health Perspect 1980;34:69-74.

7 Warheit DB, Overby LH, George G, Brody AR. Pulmonary macrophages are attracted to inhaled particles through complement activation. Exp Lung Res 1988;14:51-66.

8 Fantone JC, Ward PA. Mechanisms of lung parenchymal injury. Am Rev Respir Dis 1984;130:476-96.

9 Gadek JE, Kelman JA, Fells GA, et al. Collagenase in the lower respiratory tract of patients with idiopathic pulmonary fibrosis. N Engl JMed 1979;301:737-42.

10 Christner P, Fein A, Goldberg S, Lippman M, Abrams W, Weinbaum G. Collagenase in the lower respiratory tract of patients with adult respiratory distress syndrome. Am Rev Respir Dis 1985;131:690-5.

11 Campbell EJ, Senior RM, McDonald JA, Cox DC. Proteolysis by neutrophils. Relative importance of cell-substrate contact 
and oxidative inactivation of proteinase inhibitors in vitro. $J$ Clin Invest 1982;70:845-52.

12 Brown GM, Donaldson K. Degradation of connective tissue components by lung-derived leukocytes in vitro: role of proteases and oxidants. Thorax 1988;43:132-9.

13 Sibille Y, Lwebuga-Mukasa JS, Polonski L, Merrill WW, Ingbar DH, Gee JBL. An in vitro model for polymorphonuclear leukocyte-induced injury to extracellular matrix. $\mathrm{Am}$ Rev Respir Dis 1986;134:134-40.

14 Snider GL, Lucey EC, Stone PJ. Animal models of emphysema. Am Rev Respir Dis 1986;133:149-69.

15 Le Bouffant L, Daniel M, Martin JC. The value and limits of the relationship between cytotoxicity and fibrogenicity of various minerals. In: Brown RC, Gormley IP, Chamberlain M, Davies RC, eds. The in vitro effect of mineral dusts. London: Academic Press, 1980:333-8.

16 Daniel H, Le Bouffant L. Study of a quantitative scale for assessing the cytotoxicity of mineral dusts. In: Brown RC, Gormley IP, Chamberlain M, Davies RC, eds. The in vitro effect of mineral dusts. London: Academic Press, 1980:32-9.

17 Moores SR, Sykes SE, Morgan A, Evans N, Evans JC, Holmes A. The short-term cellular and biochemical response of the lung to toxic dusts: an in vivo cytotoxicity test. In: Brown RC, Gormley IP, Chamberlain M, Davies RC, eds. The in vitro effect of mineral dusts. London: Academic Press, 1980: 297-303.

18 Donaldson K, Brown GM. Assessment of mineral dust cytotoxicity toward rat alveolar macrophages using a ${ }^{51} \mathrm{Cr}$ release assay. Fundam Appl Toxicol 1988;10:365-6.

19 Donaldson K, Slight J, Bolton RE. In vitro fibrinolytic activity and viability of rat alveolar macrophages treated with inflammation-generating mineral dusts. Agents Actions 1987; 20:87-92.

20 Donaldson K, Slight J, Johnston PP, Bolton RE, Seaton A. Production of alveolar macrophage chemotaxins by the action of pathogenic mineral dust on serum from control rats and rats with inflammation. Thorax 1987;42:748-9.

21 Donaldson K, Bolton RE, Brown DM, et al. Studies on the cellular response in lung tissue to the inhalation of mineral dust. Edinburgh: Institute of Medicine, 1988. (Report No TM/88/ $011988^{\mathrm{b}}$.)

22 Davis JMG, Beckett ST, Bolton RE, Collings P, Middleton AP. Mass and number of fibres in the pathogenesis of asbestosrelated lung disease in rats. $B r J$ Cancer 1978;37:673-87.

23 Vincent JH, Jones AD, Johnston AM, McMillan C, Bolton RE, Cowie HA. Accumulation of inhaled mineral dust in the lung and associated lymph nodes: implications for exposure and dose in occupational lung disease. Ann Occup Hyg 1987;31: 375-93.

24 Lugano EM, Dauber JH, Daniele RP. Silica stimulation of chemotactic factor release by guinea pig alveolar macrophages. Journal of the Reticuloendothelial Society 1981;30:381-90.

25 Bell DY, Haseman JA, Spock A, McLennan G, Hook GER.
Plasma proteins of the bronchoalveolar surface of the lungs of smokers and non-smokers. Am Rev Respir Dis 1981;124:72-9.

26 Ferin J. Emphysema in rats and clearance of dust particles. In: Walton WH, ed. Inhaled Particles III. Surrey, England: Unwin Bros, 1971:283-92.

27 Lehnert BE, Valdez YE, Bomalaski SH. Analyses of particles in the lung free cell, tracheobronchial lymph nodal, and pleural space compartments following their deposition in the lung as related to lung clearance mechanisms. Ann Occup Hyg 1988;32 (suppl 1):125-40.

28 Brown GM, Donaldson K, Brown DM. Bronchoalveolar leukocyte response in experimental silicosis: modulation by a soluble aluminium compound. Toxicol Appl Pharmacol 1989; 101:95-105.

29 Bowden DH, Adamson IYR. The role of cell injury and the continuing inflammatory response in the generation of silicotic pulmonary fibrosis. $J$ Pathol 1984;144:149-61.

30 Nolan RP, Langer AM, Harington JS, Oster G, Selikoff IJ. Quartz hemolysis as related to its surface functionalities. Environ Res 1981;26:503-20.

31 Donaldson K, Kusaka Y, Cullen RT. Lymphocyte modulation by inflammatory bronchoalveolar leukocytes. FEMS Microbiol Immunol 1990;64:9-10.

32 Schmidt JA, Oliver CN, Lepe-Zuniga JL, Green I, Gery I. Silica-stimulated monocytes release fibroblast proliferation factors identical to interleukin I. A potential role for interleukin 1 in the pathogenesis of silicosis. J Clin Invest 1984; 73:1462-72.

33 Leibovich SJ, Ross R. A macrophage-dependent factor that stimulates the proliferation of fibroblasts in vitro. Am J Pathol 1976;84:501-13.

34 Postlethwaite AE, Kang AH. Collagen and collagen peptideinduced chemotaxis of human blood monocytes. J Exp Med 1976;143:1299-307.

35 Norris DA, Clark RAF, Swigart LM, Huff JC, Weston WC, Howell SE. Fibronectin fragments are chemotactic for human peripheral blood monocytes. J Immunol 1982;129:1612-8.

36 Ward PA, Hill JH. C5 chemotactic fragments produced by an enzyme in lysosomal granules of neutrophils. J Immunol 1970; 104:535-43.

37 Werb Z, Gordon S. Secretion of a specific collagenase by stimulated macrophages. $J$ Exp Med 1975;142:346-60.

38 Sablonniere B, Scharfman A, Lafitte JJ, Laine A, Aerts C, Hayem A. Enzymatic activities of bronchoalveolar lavage in coalworkers' pneumoconiosis. Lung 1983;161:219-28.

39 Chen JL, Fayerweather WE. Epidemiologic study of workers exposed to titanium dioxide. J Occup Med 1988;30:937-42.

40 Borin PA, Palinen N, Engelen JJM, Baurman WA. Spontaneous and stimulated release of tumor necrosis factor-alpha (TNF) from blood monocytes of miners with coalworkers' pneumoconiosis. Am Rev Respir Dis 1988;138:1589-94.

Accepted 11 June 1990 